\title{
Gender Affirmation Surgery: Financial Considerations ${ }^{1}$
}

\author{
Chloe W. Swearingen, Megan Donovan, Jorge Ruiz-Menjivar, and Sarah M. Ellis ${ }^{2}$
}

\section{Introduction}

Some transgender people may wish to have gender-affirming surgery to change their body and sexual characteristics to match their gender identities better. Gender affirmation is different for every trans person; some may not want any medical interventions or transition at all. At the same time, others might opt for a combination of medical procedures and nonsurgical solutions. Due to the absence of a uniform policy on insurance coverage and provider access for transgender individuals, there is a lot of confusion on the financial responsibilities for someone wishing to receive gender-affirming medical care. This factsheet provides a brief overview of gender-affirming medical care, expenses, and funding options. A glossary with key terms discussed in this publication is included at the end.

\section{Gender-Affirming Medical Procedures}

\section{Assigned Male at Birth (AMAB) Trans People}

Some trans women and other $\mathrm{AMAB}$ trans people might pursue "feminizing" surgeries for several reasons, including reducing the strain of gender dysphoria (Gijs \& Brewaeys, 2007) or "passing" as a woman for safety reasons.
Some possible gender affirmation surgeries for AMAB trans people are:

- Facial feminization surgery (FFS): A combination of surgeries that softens facial features to match feminine characteristics.

- Feminization laryngoplasty: Three different procedures that feminize voice pitch (Cavalot \& Cossu, 2015).

- Top surgery: Surgery that constructs or enhances breast tissue.

- Bottom surgery: A combination of surgeries that often includes the removal of the testes (orchiectomy) and the creation of a vagina (vaginoplasty).

These surgeries are often not covered by health insurance and represent a significant out-of-pocket expense. Facial feminization surgery ranges in cost from $\$ 19,000-\$ 45,000$. Top surgery estimations are around $\$ 8,000$, and bottom surgery estimates are about $\$ 20,000$ (The Philadelphia Center for Transgender Surgery, 2018).

Nonsurgical options such as chest inserts or specialized compression garments, and voice feminization therapy , may be more affordable (Hancock, Krissinger, \& Owen, 2011).

1. This document is FCS3355, one of a series of the Department of Family, Youth and Community Sciences, UF/IFAS Extension. Original publication date November 2020. Visit the EDIS website at https://edis.ifas.ufl.edu for the currently supported version of this publication.

2. Chloe W. Swearingen, student, Department of Family, Youth and Community Sciences; Megan Donovan, graduate student, interdisciplinary ecology, School of Natural Resources and Environment; Jorge Ruiz-Menjivar, assistant professor, Department of Family, Youth and Community Sciences; and Sarah M. Ellis, Extension agent I, M.S., family and consumer sciences, UF/IFAS Extension Citrus County; UF/IFAS Extension, Gainesville, FL 32611.

The Institute of Food and Agricultural Sciences (IFAS) is an Equal Opportunity Institution authorized to provide research, educational information and other services

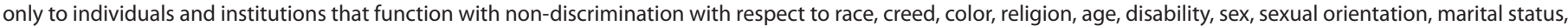

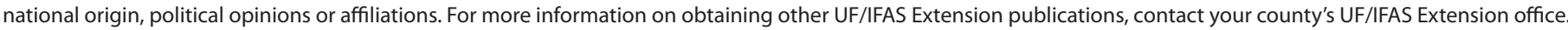
U.S. Department of Agriculture, UF/IFAS Extension Service, University of Florida, IFAS, Florida A \& M University Cooperative Extension Program, and Boards of County Commissioners Cooperating. Nick T. Place, dean for UF/IFAS Extension. 


\section{Assigned Female at Birth (AFAB) Trans People}

Trans men may opt to undergo surgeries that "masculinize" their appearance and reduce dysphoria. Possible gender affirmation surgeries for AFAB trans people include:

- Top surgery: Surgery to remove breast tissue and reshape the chest to form a "masculine" chest.

- Bottom surgery: A combination of surgeries that may include removal of the uterus and the ovaries (hysterectomy with or without an accompanying oophorectomy); and/or creation of a penis and scrotum with or without the removal of the vagina (phalloplasty or metoidioplasty with or without a vaginectomy).

Some procedures are medically necessary, such as a hysterectomy after multiple years of hormone replacement therapy (HRT). Top surgery can range from $\$ 6,000-\$ 8,000$, and bottom surgery can vary from $\$ 5,000-\$ 21,000$ depending on the procedure (The Philadelphia Center for Transgender Surgery, 2018).

Affordable, nonsurgical solutions include chest binders to reduce chest size and the use of packers, which give the appearance of external genitalia.

\section{Funding Options for Medical Transition \\ Estimating the Total Cost of Opted Medical Procedures}

Transgender patients should obtain quotes from reputable medical providers and health care institutions for medical procedures. Once they receive these quotes, they should develop a spending plan for the selected medical procedures. Insurance coverage, if any, should be taken into consideration when estimating the total cost of the surgeries. Postoperative stay and care, pre- and postoperative tests, follow-up visits, and other required documentation (e.g., letter of medical necessity) should also be included in the total cost.

\section{PAYMENT AND FINANCIAL OPTIONS}

- Trans people may use flexible spending accounts (FSAs), health savings accounts (HSAs), or health reimbursement accounts (HRAs) on the condition they provide a letter of medical necessity. The medical provider must outline how their treatment alleviates their medical concerns and how long their treatment will last, with a new letter of medical necessity (LMN) issued each year of the treatment
(FSAstore, 2019). Contributions to these accounts are tax-exempt and might be matched by patients' employers.

- Certain nonprofits provide financial assistance via microgrants or scholarships to cover medical, legal, and emergency living expenses. Also, some organizations can assist with legal identity documentation changes. Examples of these organizations and scholarships include the Jim Collins Foundation and The Darcy Jeda Corbitt Foundation, Rizi Timane Annual Transgender Scholarship, Point of Pride Annual Transgender Surgery Fund, and the Trans Love Fund.

- Other financial options for gender-affirming surgical changes include (a) unsecured loans (e.g., personal loans with no collateral), (b) secured loans (e.g., home equity line of credit), and (c) credit cards. Credit cards with introductory rates are good alternatives for borrowers who can pay off the balance before the promotional period ends and the high-interest rate kicks in. For any of the financing options, it would be essential to compare interest rates and terms, develop a prepayment plan, and review your credit history and score. Based on your creditworthiness, it might be appropriate to improve, repair, or build your credit before applying for loans or credit cards.

- Many trans people may choose to have surgeries outside of the United States or initiate HRT without a physician's guidance (Rotondi et al., 2013). While this might be seen as a strategy to save money on gender-affirming procedures, the quality of care may be compromised. These procedures should always be pursued under the consultation of primary care and other medical and health professionals.

\section{Summary}

Battling gender dysphoria can be a lifelong struggle for trans individuals. While some trans people do not desire any procedures, gender-affirming surgeries may alleviate gender dysphoria. However, cost and access to treatment may be barriers for many who wish to have surgery. There are less expensive alternatives to surgery available. It is important to note that gender-affirming surgery involves a complex set of financial considerations, and gender identity expression for trans people is not exclusively dependent on surgery.

\section{Glossary}

- The term Assigned Male at Birth (AMAB) is based on the presence of external genitalia. AMAB trans individuals are women who do not identify with the sex (i.e., 
male) designated at birth. Synonyms include designated male at birth and male assigned at birth.

- Assigned Female at Birth (AFAB) refers to sex assigned at birth based on the presence of internal genitalia. AFAB trans men do not identify with the sex (i.e., female) assigned at birth. Alternate words include designated female at birth and female assigned at birth.

- Gender dysphoria refers to an emotional state of distress related to one's biological sex or gender.

- The term "passing" indicates that someone cannot differentiate a transgender individual from a cisgender (gender identity corresponds with gender designated at birth) individual based on appearance or secondary sex characteristics, such as voice.

\section{References}

Bebinger, M. (2014). How Transgender People Are Changing Their Voices. WBUR. Retrieved from https://www.wbur. org/commonhealth/2014/08/19/transgender-voices

Cavalot, A. L., \& Cossu, D. (2015). Feminization Laryngoplasty: Surgical Therapy. In C. Trombetta, G. Liguori, \& M. Bertolotto (Eds.), Management of Gender Dysphoria (pp. 135-144). Milan: Springer Milan. DOI: 10.1007/978-88-470-5696-1

FSAstore. (2019). Transgender Counseling or Surgery: FSA Eligibility. Retrieved from https://fsastore.com/FSAEligibility-List/T/Transgender-Treatment-or-Surgery-E717. aspx

Gijs, L., \& Brewaeys, A. (2007). Surgical Treatment of Gender Dysphoria in Adults and Adolescents: Recent Developments, Effectiveness and Challenges. Annual Review of Sex Research, 18(1), 178-224.

Hancock, A. B., Krissinger, J., \& Owen, K. (2011). Voice Perceptions and Quality of Life of Transgender People. Journal of Voice, 25(5), 553-558.

Khadija, M. (2016). Transgender Reproductive Choice and Fertility Preservation. AMA Journal of Ethics, 18(11), 1119-1125.

Reeves, C., Deutsch, M. B., \& Stark, J. W. (2019). Hair Removal. Center of Excellence for Transgender Health. Retrieved from http://transhealth.ucsf.edu/ trans?page=guidelines-hair-removal
Rotondi, N. K., Bauer, G. R., Scanlon, K., Kaay, M., Travers, R., \& Travers, A. (2013). Nonprescribed Hormone Use and Self-Performed Surgeries: "Do-It-Yourself" Transitions in Transgender Communities in Ontario, Canada. American Journal of Public Health, 103(10), 1830-1836.

Schulz, S. L. (2018). The Informed Consent Model of Transgender Care: An Alternative to the Diagnosis of Gender Dysphoria. Journal of Humanistic Psychology, 83(1), 72-92. DOI: $10.1177 / 0022167817745217$

The Philadelphia Center for Transgender Surgery. (2018). Female to Male Price List. Retrieved from http://www. thetransgendercenter.com/index.php/femaletomale1/ftmprice-list.html

University of Utah Health. (2018). Fertility for Trans Women (MTF Fertility). Retrieved from https://healthcare. utah.edu/transgender-health/fertility.php

World Professional Association for Transgender Health. (2011). Standards of Care for the Health of Transsexual, Transgender and Gender Nonconforming People. Retrieved from https://www.wpath.org/media/cms/Documents/ Web\%20Transfer/SOC/Standards\%20of\%20Care\%20 V7\%20-\%202011\%20WPATH.pdf 